\title{
O futuro do jornal
}

\section{RESUMO}

Este é um estudo analítico que apresenta as principais características discutidas pelos proprietários de jornais brasileiros para antever o fim do jornal-papel, tendo como principal motivo o advento da internet. A análise baseia-se em reportagens publicadas pela Associação Nacional de Jornais do Brasil (ANJ), em alguns pesquisadores internacionais que tratam do assunto e no levantamento de dados a partir de textos da Internet, de autoria de jornalistas..

\section{PALAVRAS-CHAVE}

jornal-papel

internet

desaparecimento

\section{ABSTRACT}

This is an analytical study, which presents the main features discussed by the owners of Brazilian newspapers to predict the end of yours products. The main reason for this probability is the advent of the internet. Analysis was based on reports published by the Brazil's National Association of Newspapers (ANJ), for some internacional authors that treat the subject and in some texts of the internet, written by journalists.

\section{KEY WORDS}

paper-paper

internet

disappearance

\section{Beatriz Dornelles}

Professora do Programa de Pós-Graduação em Comunicação da PUCRS/RS/

$B R$

biacpd@pucrs.br
A possibilidade do desaparecimento dos jornais em um futuro relativamente próximo é uma das questões mais debatidas quando se trata de explorar as perspectivas da mídia diante das transformações tecnológicas que ocorrem desde o advento dos computadores pessoais e da internet. Isto foi o que constatamos na leitura de entrevistas divulgadas pela Associação Nacional de Jornais, a conhecida ANJ.

Philip Meyer, repórter aposentado do grupo knight Ridder, que publica mais de uma dezena de jornais nos EUA, professor da Universidade da Carolina do Norte e autor do livro "Os jornais podem desaparecer?", da Editora Contexto, em entrevista ao site www. nominimo.com.br, diz que o surgimento da internet comercial lançou o jornalismo impresso na pior crise de sua história. $\mathrm{O}$ drama não se conta em relatórios trimestrais ou na flutuação de ações nas Bolsas; tampouco é medido pela quantidade de demitidos nas redações de todo o mundo. Tudo é conseqüência: o drama é que adolescentes e jovens adultos, em meados da primeira década do século, lêem muito menos jornais do que liam. É nesta idade que se cria o hábito - e o hábito desta turma é se informar pela internet.

A cada geração, o número de consumidores de jornais diminui - e a curva está se inclinando numa velocidade estonteante. Ponha-se num gráfico a diminuição de circulação dos jornais nos EUA, por exemplo. E o fim tem data marcada: 2043. Apesar das previsões, dificilmente isto acontecerá. Com base numa rigorosa revisão do desempenho das empresas jornalísticas desde a década de 1970 e tomando como referência os conceitos sobre competitividade e estratégia empresarial de Michael Porter, um dos mais requisitados especialistas no assunto, que ele elabora os dois cenários que a seu ver balizarão a evolução dos jornais.

Segundo o pesquisador norte-americano, os jornais desfrutaram de um monopólio natural em seus respectivos mercados locais, em particular os pequenos e médios, e por eles a informação trafegava dos varejistas locais até seus clientes, proporcionando uma lucratividade superior à média. A diversificação das mídias mudou esse quadro de forma irreversível. A redução da circulação e o surgimento de alternativas para os anunciantes antecederam a internet. Entretanto, a principal resposta do setor de jornais à ameaça da tecnologia substituta tem sido reduzir custos e aumentar preços.

A manutenção dessa política, segundo Meyer, leva ao cenário do "pegue-o-dinheiro-e-corra, pela qual os controladores das empresas aumentam os preços e simultaneamente tentam manter sua rota de lucratividade com as técnicas usuais: diminuir o espaço editorial, cortar pessoal, reduzir a circulação em 
áreas remotas ou de baixa renda, adiar a manutenção e a melhoria na estrutura de capitais e manter baixos salários. Essa estratégia pode funcionar, mas Meyer acredita que levará a um triste fim.

O segundo cenário supõe que os controladores atuais das empresas jornalísticas ou seus sucessores "aceitarão a realidade da nova competição, investirão no aprimoramento de produtos que explorem totalmente o poder da mídia impressa, incluindo a mídia digital" (Mayer, 2007). Adotar essa estratégia supõe ver as tecnologias substitutivas não como ameaça, mas como oportunidade.

Para que essa estratégia seja bem-sucedida, contudo, Meyer sustenta que o jornalismo como negócio não deve ser entendido como a intermediação entre leitores e anunciantes, mas como a produção de influência. Isso o leva a sustentar que a melhor maneira de garantir o futuro dos jornais seria conservar sua influência e pagar os custos das experiências radicais necessárias para aprender quais novas formas de mídia serão viáveis num mercado muito mais complexo que no passado, no qual a informação em si não é mais escassa e, portanto, tem menos valor, enquanto o bem cobiçado não é nem percentagem da circulação, nem a percentagem de leitores, mas a percentagem da quantidade finita da atenção do público.

Encarada por esse ângulo, nos últimos anos e atualmente a principal questão estratégica para os jornais, segundo o pesquisador, passa a ser "descobrir e compreender as populações segmentadas onde há maior viabilidade de conquistar essa confiança e exercer influência".

\section{Mercado brasileiro}

E foi dentro desse espírito que os empresários brasileiros mudaram de atitude em relação aos jornais e buscaram novidades para o mercado em todos os aspectos, destacando-se uma nova visão de jornalismo participativo, com mudanças em estratégias publicitárias e também na distribuição do jornal, no seu aspecto gráfico, na busca de leitores jovens, na formação continuada dos jornalistas e na execução de programas que inserem o jornal na sala de aula, visando contribuir para formação dos estudantes brasileiros.

Segundo destaca o editor executivo de interatividade do site Globo Online, Aloy Jupiara, não se deve subestimar a importância e qualidade do conteúdo enviado pelo leitor, pois ele sabe muito, porque sabe o que é a vida na sua rua, no seu bairro, na sua cidade, no seu país. Além disso, o leitor tem sim parâmetros éticos que devemos respeitar. "O jornalismo participativo é uma riqueza de informações, de novos pontos de vista, de novas histórias".

Sobre a circulação, conforme o vice-presidente de Circulação da Associação Norte-Americana de Jornais (NAA), John Murray1: "A entrega domiciliar ainda é o grande canal de vendas nos Estados Unidos". Lá, $70 \%$ da circulação total dos jornais diários que são publicados de segunda a sexta-feira são entregues nos endereços dos assinantes. Dados de 2005, conforme Murray, mostram que de cada 10 leitores, 7 lêem notícias pela internet. Isso faz com que os grupos de comunicação dos EUA estejam investindo nessa nova mídia e também em jornais segmentados, como os dirigidos às colônias de língua hispânica.

Ainda com relação ao comportamento dos assinantes, o exemplo do jornal Meia Hora, do Rio de Janeiro, transformou-se em dois anos em um caso de sucesso. Hoje ele é o quarto mais vendido no país e o segundo em bancas. O Meia Hora surgiu como um segundo título do Grupo O Dia, um jornal barato (preço de capa $R \$ 0,50)$ e portátil. Seus principais objetivos eram resgatar as pessoas que haviam abandonado a leitura de jornais por diversos motivos, e atrair novos leitores. Inicialmente, seus produtores pensavam atingir 100 mil exemplares em seis anos, mas a marca foi alcançada em apenas dois anos. Por isso, em 2005, o Rio de Janeiro foi o único estado do país a ter um aumento no número de seus leitores².

A RBS também buscou mudanças para enfrentar a diminuição do índice de leitores de jornal. Em 2005, entregou a produção do seu suplemento juvenil a uma empresa especializada, que já editava um jornal-revista destinado a esse tipo especial de leitor, a Kzuka. Na verdade, a RBS adquiriu parte do controle acionário da Kzuka, uma empresa de comercialização e marketing fundada em 2000 por Fernando Tormaim. Desse modo, o pessoal da Kzuka instalou-se na Redação de Zero Hora, onde passou a produzir conteúdo não só para esse jornal, como também para as demais publicações do grupo RBS.

Mesmo assim, a Kzuka continuou editando o seu próprio jornal-revista, destinado ao público jovem das classes A e B e distribuído nas escolas de Porto Alegre e de outras cidades do Rio Grande do Sul. Segundo Fernando Tormaim, o segredo do sucesso desse tipo de comunicação está no fato de a redação ser constituída por jovens na faixa dos 23 anos de idade, que falam a linguagem do público-alvo. A fórmula editorial de sucesso do jornal-revista Kzuka privilegia o projeto gráfico, com muitas imagens. $\mathrm{O}$ teor das matérias, sempre curtas e de fácil leitura, procura manter um equilíbrio de conteúdo nacional e local. Uma característica é que as matérias do suplemento buscam sempre fazer uma integração com outros cadernos do jornal em que está inserido, e também com os demais veículos da Kzuka: site, a rádio online e outros. O resultado são 20 mil exemplares do jornalrevista distribuídos gratuitamente todas as semanas, além dos suplementos encartados nos jornais da RBS.

$\mathrm{Na}$ publicidade, os jornais estão cada vez mais agressivos em suas estratégias de conquistar o mercado publicitário. Por exemplo, o tradicionalíssimo 
O Estado de São Paulo permitiu pela primeira vez em seus 128 anos, a inserção de uma marca publicitária no cabeçalho de uma página. Foi o que aconteceu com a campanha do automóvel Citroën $\mathrm{C} 3$, em que a numeração convencional da página C3 - do caderno Cidades - foi substituída pelo logotipo do carro. Aproveitou-se a coincidência de a numeração da página ser a mesma que dá nome ao carro para uma campanha que venceu o Prêmio Mídia Estadão 2007.

\section{Na publicidade, os jornais estão cada vez mais agressivos em suas estratégias de conquistar 0 mercado publicitário}

Também um novo projeto para aumentar as vendas publicitárias dos jornais foi colocado em prática em 2008: funcionamento de uma empresa com o objetivo de vender em bloco seus espaços publicitários, de modo a atrair grandes anunciantes que hoje estão afastados da imprensa diária. O modelo baseia-se na Rede Nacional de Jornais, criada em 1994 pela Associação Norte-americana de Jornais para enfrentar nos Estados Unidos o mesmo problema de queda na participação dos jornais no mercado publicitário.

Outra novidade dos jornais é a preparação do "repórter multimídia". Esse profissional atua, ao mesmo tempo, em jornal, rádio, televisão e internet. Trata-se de jornalistas polivalentes que podem produzir conteúdo para toda essa diversidade. Desde o final da década passada, a RBS tem oferecido cursos de treinamento para jornalistas que queiram aprender seu ofício em mídias diferentes daquelas para as quais já trabalham. Os profissionais produzem para diferentes mídias e recebem pagamentos mais elevados em relação aos demais ${ }^{3}$.

Na área da Educação, o Brasil possui diversos exemplos bem-sucedidos de inclusão da leitura do jornal nas escolas, como estratégia de conquista de novos leitores. Um projeto do jornal O Povo, do Ceará, por exemplo, executado por uma equipe de educadores, historiadores e jornalistas, beneficiou mais de 250 escolas públicas e particulares, faculdades, secretarias municipais de Educação e ONGs do Ceará.

O projeto "O Povo na Educação" desenvolve-se por meio do envio de exemplares do jornal para as escolas, palestras sobre a formação do leitor, a mídia e a educação, assessoria pedagógica, colaboração na produção do jornal escolar, publicação da coluna $\mathrm{O}$ Povo na Educação e do caderno infantil Clubinho, realização de parcerias como a existente com a Unicef, e promoção de concursos, entre outras atividades. Graças a essas e muitas outras iniciativas das empresas jornalísticas, em agosto de 2008 o Jornal ANJ publicou uma série de reportagens mostrando o crescimento dos jornais em todo o país, representando uma fase de resultados excepcionais no setor, com boas perspectivas de continuar em 2009. Dados da ANJ - Associação Nacional dos Jornais - apontam um aumento de $89,03 \%$ na circulação paga dos jornais nos últimos 17 anos.

Em agosto de 2006, a revista britânica The Economist publicou polêmica reportagem de capa sob o título "Quem matou o jornal?" No texto, traçava os mais pessimistas prognósticos para os jornais impressos em todo o planeta, face ao crescimen-to do acesso às novas tecnologias . A reportagem anunciou: "De todos os 'velhos' meios de comunicação social, os jornais são os que mais têm a perder frente à internet. A circulação vem caindo na América, Europa Ocidental, América Latina, Austrália e Nova Zelândia durante décadas. Mas nos últimos anos, a web acelerou o declínio". Para completar, a revista lembrou a profecia feita por Philip Meyer (autor de "Os jornais podem desaparecer?" Editora Contexto), para quem no primeiro trimestre de 2043 o último leitor norte-americano tossirá ao lado da derradeira edição impressa de um jornal.

Nem a The Economist nem Meyer conseguiram prever que nos países emergentes uma nova situação subverteria as previsões matemáticas e os dados estatísticos. Ao contrário do anunciado, o aumento significativo da circulação em países como China, índia e Brasil refletiu-se no cômputo global, resultando em um pequeno aumento no mundo todo (Teixeira e Manzano, 2008, p. 23).

Com base na variação de circulação dos jornais filiados ao Instituto Verificador de Circulação (IVC), a ANJ estima que no em 2007 tenha sido comercializada a média diária de 8,08 milhões de exemplares de jornais em todo o país. Nunca os jornais circularam tanto no Brasil desde 1990 em números absolutos, embora o número de leitores brasielrios ainda seja tímido se comparado aos cinco maiores mercados estrangeiros, segundo informações da Associação Mundial dos Jornais (WAN, World Association of Newspapers):

$\left.1^{\circ}\right)$ China, 107 milhões de exemplares vendidos diariamente;

$\left.2^{\circ}\right)$ Índia, 99 milhões de exemplares;

$\left.3^{\circ}\right)$ Japão, 68 milhões;

$\left.4^{\circ}\right)$ EUA, quase 51 milhões

$5^{\circ}$ ) Alemanha, 20,6 milhões

Os números dividem o mundo em duas tendências: nas regiões mais desenvolvidas, em que os jornais impressos eram soberanos, como Europa e Estados Unidos, a circulação paga caiu; já em mercados mais jovens e em desenvolvimento, como América Latina e Ásia, a circulação dos jornais pagos aumentou. Na região latino-americana, o Brasil, com 11,8\%, obteve 
resultado acima da média de $6,4 \%$ do continente americano.

De acordo com levantamentos feitos pela diretoria da ANJ e do IVC, "um conjunto de fatores impulsionou o expressivo crescimento do meio jornal no Brasil, com destaque para a competitividade do mercado que gerou reformulações gráficas e de conteúdo, bem como a segmentação com novos cadernos e lançamento de promoções" ${ }^{\prime \prime}$. Além disso, o aumento da renda média e do consumo no país, em decorrência dos bons resultados econômicos nos últimos anos e o surgimento ou consolidação de jornais com preços acessíveis às classes $\mathrm{C}$ e D.

\section{Os jornais tradicionais apostam} no investimento em projetos especiais para conquistar novos leitores, como o lançamento de revistas, distribuídas com o jornal dominicial. Foi o que fizeram os jornais Folha de $S$. Paulo, 0 Estadáo e A Tarde, da Bahia. E consolidam-se os jornais gratuitos, seguindo tendência na Europa, em especial Espanha, Inglaterra e França. Em São Paulo temos, hoje, o mais antigo, 0 MetrôNews, e os mais recentes, Destak e PubliMetro

Ao confrontar as dez maiores circulações pagas de 2006 com as mesmas posições em 2007, percebe-se que, no Brasil, os jornais populares, de fato, começam a ganhar espaço no ambiente antes dominado pelos diários tradicionais. Entre os dez mais bem colocados no ranking, três derivam da fórmula notícia rápida, fait divers e bom preço: Extra (Rio de Janeiro, R $\$ 1,00$ ), Super Notícia (Belo Horizonte, R\$ 0,25) e Meia Hora (Rio de Janeiro, $R \$ 0,50)$. Outro fenômeno ocorrido no setor foi o surgimento de jornais gratuitos, com estratégias agressivas de marketing e distribuição eficiente, em especial em São Paulo, com a chegada de dois novos produtos no mercado, o Destak e o PubliMetro, seguindo uma tendência verificada nos países europeus, onde os jornais distribuídos gratuitamente não apenas cresceram nos últimos anos como tomaram lugar, entre o público leitor, dos periódicos pagos ${ }^{6}$.

O mesmo, no entanto, não aconteceu no Brasil. Aqui a circulação paga dos jornais tradicionais também aumentou significativamente entre 2006 e 2007. Com exceção da Folha de São Paulo e do gaúcho Correio do Povo, todos os jornais tradicionais entre as 10 melhores posições viram aumentar sua média diária de circulação paga nos últimos dois anos. Atualmente, os dez maiores jornais brasileiros por circulação paga são :

$\left.1^{\circ}\right)$ Folha de São Paulo (standart): 302.595

$2^{\circ}$ ) O Globo (standart): 280.329

$3^{\circ}$ ) Extra (standart): 273.560

$4^{\circ}$ ) O Estado de S. Paulo (standart): 241.126

$5^{\circ}$ ) Super Notícia (tablóide): 238.611

$\left.6^{\circ}\right)$ Meia Hora (tablóide): 205.768

$7^{\circ}$ ) Zero Hora (tablóide): 176.412

$8^{\circ}$ ) Diário Gaúcho (tablóide): 155. 328

$\left.9^{\circ}\right)$ Correio do Povo (tablóide): 154.188

$10^{\circ}$ ) Lance (tablóide): 112. 625

Assim, o que podemos observar para o futuro no mercado brasileiro de jornais é que se expande o mercado dos jornais populares, seguindo a fórmula: preço baixo, fotos de mulheres com pouca roupa, vasta cobertura de crimes, destaque para o futebol, informações úteis e de serviços públicos.

\section{Considerações Finais}

Os jornais tradicionais apostam no investimento em projetos especiais para conquistar novos leitores, como o lançamento de revistas, distribuídas com o jornal dominicial. Foi o que fizeram os jornais Folha de $S$. Paulo, O Estadão e A Tarde, da Bahia. E consolidam-se os jornais gratuitos, seguindo tendência na Europa, em especial Espanha, Inglaterra e França. Em São Paulo temos, hoje, o mais antigo, o MetrôNews, e os mais recentes, Destak e PubliMetro.

O Destak está com 150 mil exemplares diários e, se fosse auditado pelo IVC, estaria na lista dos 10 maiores jornais do Brasil em circulação. Os jornais clássicos, para enfrentar a concorrência com os populares, apostam no aprofundamento da notícia, a reunião de diversas informações no mesmo produto, a visão mais crítica da realidade e a possibilidade efetiva de formação de opinião. A estratégia indicada para o futuro seria copiar a fórmula das revistas semanais.

No primeiro semestre de 2008, a tiragem dos jornais brasileiros cresceu, em média, 8,1\%, comparado a igual período de 2007. Na captação de investimentos publicitários pelos jornais, em 2007, os jornais brasileiros ficaram comm uma fatia de $16,38 \%$ do bolo 
publicitário brasileiro, o que representou um aumento dessa participação depois de muitos anos de queda. Em maio de 2008, a fatia do bolo já havia chegado a $17,77 \%$, em valores acumulados e comparados a igual período de 2007. O maior crescimento na captação de investimentos publicitários deu-se na Região Nordeste, com $48,61 \%$. Depois vieram a Sul e Sudeste (exceto Rio de Janeiro e São Paulo), com 44,20\%; o Centro-Oeste, com 33,74\%; São Paulo, com 12,37\%; e o Rio de Janeiro, com $12,04 \%$.

\section{No primeiro semestre de 2008, a tiragem dos jornais brasileiros crescev, em média, 8,1\%, comparado a igual período de 2007}

Diante deste quadro, entendo que falta aos jornaislaboratórios ousadia em seus conteúdos. Os estudantes devem poder praticar o jornalismo popular, que está em ampla expansão em todo o país. De maneira geral, excetuando-se alguns casos, os jornais-laboratórios ou trabalham apenas com a grande reportagem de temas mais apropriados aos intelectuais ou repetem a fórmula de jornais empresariais. Na minha opinião, isso precisa mudar para melhor preparar nossos estudantes de jornalismo $\square$ FAMECOS

\section{NOTAS}

1 Palestra realizada no VI Seminário Nacional de Circulação, organizada pelo Comitê de Mercado Leitor da ANJ, entre os dias 17 e 18 de setembro de 2007, em São Paulo.

2 Henrique Freitas, Editor Executivo do Meia Hora.

3 Declaração de Marcelo Rech, na época Diretor de Redação do jornal Zero Hora, publicada no Jornal ANJ, em outubro de 2007.

4 Reportagem de Fabrício Teixeira e Rodrigo Manzano, intitulada "A gramatura do Papel-jornal", pág. 23. Revista Imprensa, agosto de 2008, ano 21, $\mathrm{n}^{\mathrm{o}} 237$.

5 Palavras utilizadas por Ricardo Costa, diretor-geral do IVC, em reportagem à Revista Imprensa, agosto/2008 e dados levantados pela autora junto à ANJ.

6 Fonte: ANJ, baseada em dados do IVC - Ano: 2007
MURRAY, John. Palestra realizada no VI Seminário Nacional de Circulação, organizada pelo Comitê de Mercado Leitor da ANJ, entre os dias 17 e 18 de setembro de 2007, em São Paulo.

TEIXEIRA, Fabrício; MANZANO, Rodrigo. A gramatura do Papel-jornal. Revista Imprensa, agosto de 2008, ano 21, n 237, p. 23.

TRAQUINA, Nelson. O que é Jornalismo. Lisboa: Ed. Quimera, 2007.

Sites:

Associação Mundial dos Jornais

www.nominimo.com.br

www.globo.com

www.rbs.com.br

Jornais analisados:

Meia Hora, O Dia, Zero Hora, O Estado de S. Paulo, O Povo, A Tarde (BA), MetrôNews, Destak, PubliMetro, Jornal ANJ, Folha de São Paulo, O Globo, Extra, Super Notícia, Diário Gaúcho, Correio do Povo e Lance (tablóide).

\section{REFERÊNCIAS}

MEYER, Philip. Os jornais podem desaparecer? São

Paulo, Ed. Contexto, 2007. 